\title{
Análise das relações intersetoriais da economia paraense e seus efeitos multiplicadores
}

Ricardo Bruno N. dos Santos - Graduado em Ciências Econômicas pela Universidade Federal do Pará (2002) mestre em Ciências Florestais pela Universidade Federal Rural da Amazônia (2006). Doutorando do programa de Pósgraduação do curso de Economia Aplicada da Universidade Federal de Viçosa. E-mail: ricardobns@gmail.com

Airton Lopes Amorin - Mestre na área de Desenvolvimento Econômico pela Universidade Federal de Viçosa (2008), e doutorando em Economia Aplicada pela Universidade Federal de Viçosa (UFV). E-mail: aimorim2007@yahoo.com.br

Antônio Cordeiro - Graduado em Agronomia pela Universidade Federal do Ceará (1983), e doutor em Economia Aplicada pela Universidade Federal de Viçosa (1993). Atualmente é professor Associado III da Universidade Federal Rural da Amazônia e atua no ensino e orientação nos cursos de graduação e de pós-graduação (Mestrado em Ciências Florestais e Doutorado em Ciências Agrárias). E-mail: acsantana@superig.com.br

\section{Resumo}

Neste trabalho identificam-se setores-chave para investimento na estrutura produtiva do Estado do Pará, utilizando métodos de índices de ligação de Rasmussen-Hirschman (IRH), dos índices puros (GHS) e do campo de influência, bem como os multiplicadores de produto, renda e emprego. Segundo a análise IRH e GHS, os setores considerados chave foram Soja e milho; Outras culturas; Metalsiderúrgico; Adubo e fertilizantes; e Serviços. A atividade agropecuária, além de ter dois setores considerados chave, teve três setores que se destacaram nos efeitos multiplicadores: Fruticultura; Outras culuras; e Aves, bovinos e suínos.

\begin{abstract}
In this work the key-sectors for investment in the state of Pará are identified using the Rasmussen-Hirschman, GHS indexes, the influence field índex methodologies and the multipliers of output, income and employment. According to the RasmussenHirschman index, and GHS, the key-sectors are Soybeans and corn; Other cultures; Metal-steel industry; Manure and fertilizer; and Services. Agricultural activity in addition to two key-sectors considered, had three outstanding sectors in the multiplier effects (Fruits; Other cultures; and Poultry, cattle and pigs).
\end{abstract}

\section{Palavras-chave}

Insumo-Produto. Setores-chave. Análise Estrutural de Impacto.

\section{Keywords}

Input-Output. Key-sectors. Structural Analysis of Impact 


\section{INTRODUÇÃO}

A análise da estrutura produtiva de estados e países estão ligados ao conhecimento mais aprofundado da interdependência presente nas relações intersetoriais. Esse conhecimento do grau de articulação entre as atividades de produção é extremamente importante no direcionamento e na formulação de políticas de desenvolvimento regional. É importante considerar ainda que as transferências de fatores produtivos e mercadorias entre estados de um país ocorrem de forma mais intensa quando comparadas aos fluxos de produtos e insumos entre os países. Isso porque os custos de transporte são menores relativamente, além da inexistência de barreiras comerciais ao comércio inter e intraestadual. As estruturas de produção estaduais revelam, portanto, maior interdependência relativamente.

A identificação do modo como o crescimento econômico ocorre em determinado estado, no que se refere à forma como os setores econômicos de determinada região desfrutam, simultaneamente, desse crescimento e de seu dinamismo, é importante, pois as forças de mercado não são capazes, atuando sozinhas, de fazer com que todos os setores respondam ao estímulo inicial de determinado setor. É aí que se insere a relevância da intervenção governamental via investimentos em setores com maior poder de encadeamento. Entretanto, a promoção do crescimento econômico equilibrado torna-se inviável diante da dificuldade de investimentos em todas as atividades ao mesmo tempo. Segundo a teoria de desenvolvimento econômico de Hirschman (1958), diante da escassez de recursos para os investimentos necessários, a definição do alvo para investir parte da avaliação do estímulo/pressão que determinada atividade econômica gera, possibilitando que outro investimento ocorra. A ideia central por parte dessa estratégia é de que a produção em um setor estimula, via vazamentos, o crescimento das demais atividades econômicas. Portanto, a importância de determinado setor está além de sua participação na renda da economia, uma vez que sua produção é capaz de elevar a produção da economia num montante múltiplo da elevação de sua produção. A produção em um setor estimula o crescimento das demais atividades, o que provoca desequilíbrio na economia. Nesse contexto, justifica-se a identificação das atividades econômicas que indicam maiores condições de suporte e estímulo ao desenvolvimento do estado. O objetivo é apontar as principais ligações intersetoriais que se configurem alvos de investimentos, promovendo, assim, o crescimento econômico de forma equilibrada.
Especificamente, este trabalho avalia os impactos gerados por alterações da demanda final nas atividades econômicas que compõem o sistema produtivo do Pará, mensurando o poder de encadeamento dos setores, dada as suas estruturas tecnológicas. Numa segunda etapa, identificam-se os setores que podem causar maiores impactos na economia estadual, mediante mudanças em suas estruturas de produção. Para isso, ressalta-se a importância dos modelos de insumo-produto, mais especificamente a matriz inversa de Leontief, que permite conhecer, de forma detalhada, os impactos de variações na demanda final das atividades produtivas do Estado, resultantes de ações de políticas públicas.

Quanto à estrutura do trabalho, além da introdução e das conclusões, constam mais três seções. A seção 2 discute brevemente a teoria de insumoproduto, seguida da seção 3, que aborda o modelo analítico de índices de ligação de Rasmussen-Hirschman, dos índices puros de ligação, da metodologia de campo de influência e dos multiplicadores. Na seção 4 discutem-se os resultados obtidos.

\section{TEORIAS DA ANÁLISE DE INSUMO-PRODUTO}

Leontief (1983) aplica a teoria econômica do equilíbrio geral (interdependência geral) em uma análise empírica das inter-relações entre atividades econômicas de uma nação, concentrando-se na ideia de fluxo circular. A teoria de insumo-produto baseia-se em alguns pressupostos que correspondem a uma simplificação do modelo walrasiano, como: equilíbrio geral na economia a um dado nível de preços; ausência de ilusão monetária; retornos constantes à escala e preços constantes. Nesse contexto, Leontief criou a matriz de insumo-produto (MIP ${ }^{1}$ ), com o intuito de descrever os fluxos de bens e serviços entre todos os setores da economia de um país, durante certo período, em valores monetários. Embora criada inicialmente para estudo das economias das nações, a matriz de insumo-produto vem sendo adaptada para identificar as relações intersetoriais presentes nas economias de regiões ou estados. O modelo básico empregado em ambas as dimensões é semelhante e ocorre no sistema articulado por atividades de grupo de setores.

$\mathrm{Na}$ matriz insumo-produto apresentam-se estimativas da demanda intermediária que permitem a construção da matriz de coeficientes técnicos, a qual informa, em termos relativos, a requisição de insumos necessários a cada setor, para

A MIP utilizada neste trabalho corresponde a do ano de 1999 a preços básicos, atualizada a preços de 2003. 
que realize sua produção. A partir da matriz de insumo-produto é também possível a definição da matriz de efeitos diretos e indiretos, cujos elementos indicam os efeitos totais sobre a produção de um dado setor, advindos de uma variação em qualquer componente da demanda final. A ideia é de que um choque na demanda final de um setor exigirá, por parte deste, que altere o seu volume de insumos nas proporções indicadas na matriz de coeficientes técnicos para responder a essa demanda. Considerando-se que estes insumos são fornecidos por outros setores, estes também sofrerão alterações em suas vendas, e os efeitos da variação inicial na demanda final se propagam por todo o aparelho produtivo da economia.

Trabalhos como os de Santana (1994), Valverde et al. (2003) e Silva (2004), detalham mais toda a álgebra matricial envolvida na construção da MIP.

$\mathrm{Na} \mathrm{MIP}$, os vetores-linha indicam os fluxos de vendas da produção do setor, na qual se pode observar a distribuição da produção de um dado setor com os demais setores (demanda intermediária) e os volumes de produção do setor canalizados para consumo das famílias, do governo, para exportações e formação bruta de capital fixo (demanda final). Os vetores-coluna apontam as compras do setor necessárias para sua produção, considerando que a produção de determinado setor requer insumos provindos de outros setores (nacionais e importados), além do pagamento de impostos, e remuneração dos insumos primários (valor adicionado). Definindo a parcela de insumo-produto do setor i como diretamente proporcional à produção do setor $j$, tem-se que:

$$
X_{i j}=a_{j} X_{j}
$$

em que ${ }^{a_{\ddot{j}}}$ é o coeficiente técnico direto de produção que indica a quantidade de insumo do setor i necessária para a produção de uma unidade de produto final do setor $\mathrm{j}$.

Com base na equação (1), pode-se definir o sistema aberto de Leontief:

$$
\sum_{j=1}^{n} a_{i j} X_{j}+Y=X_{i}, \mathrm{i}=1,2, \ldots, \mathrm{n} .
$$

Em termos matriciais, a equação (2) consiste em:

$$
A X+Y=X
$$

em que A é a matriz de coeficientes diretos de insumo de ordem ( $\mathrm{n} \times \mathrm{n}) ; \mathrm{X}$, um vetor-coluna de ordem ( $\mathrm{n} \times 1$ ) de valor bruto da produção; e Y, um vetor-coluna de ordem ( $\mathrm{n} \times 1)$ de demanda final total.

Os coeficientes que compõem a matriz de coeficientes técnicos de produção encontrados na matriz A são definidos como:

$$
a_{i j}=\frac{x_{j}}{X_{j}}
$$

em que $a_{i j}$ define quanto, para cada unidade de produção total do setor j, este demanda do setor i. Os coeficientes técnicos são positivos e inferiores à unidade. Além disso, cada coluna da matriz A representa a estrutura tecnológica do setor correspondente, de acordo com os pressupostos de retornos constantes de escala e utilização dos insumos em proporções fixas.

Considerando a demanda final $(\mathrm{Y})$ como exógena, obtém-se a produção total $(\mathrm{X})$ a partir da equação (2.2), da seguinte forma:

$$
X=(\mathrm{I}-\mathrm{A})^{-1} \mathrm{Y}
$$

em que (I-A) ${ }^{-1}$ é a matriz de coeficientes técnicos diretos e indiretos, ou matriz de efeitos globais, conhecida também como matriz inversa de Leontief, que mostra todos os efeitos sobre todo o aparelho produtivo da economia, decorrentes de uma alteração quantitativa em qualquer um dos componentes da demanda final.

As colunas da demanda final (Y) constituem as compras realizadas pelos setores do resto do Brasil, de produtos do Pará, que serão destinadas ao consumo final, e estão agregadas, para facilidade de aplicação da metodologia. A estrutura de insumos para o setor Soja e milho (j) define-se como:

$$
X_{1}=x_{1} \ldots+x_{7,1}+\ldots+x_{6,1}+x_{\nabla, 1}+m_{1}^{R}+m_{1}^{P}+T_{1}+H_{1}
$$

Por outro lado, a demanda por produtos de origem nesse setor pode ser obtida por:

$$
X_{1}=x_{1} \ldots+x_{1,7}+\ldots+x_{1, \emptyset}+x_{1,7}+Y_{1}^{\Theta}+Y_{1}^{O}
$$

em que $Y_{1}^{\Theta}$ representa a demanda final do Pará por produtos do setor 1 e $Y_{1}^{\boldsymbol{O}}$ define a demanda final do resto do Brasil por produtos do setor 1. 


\section{METODOLOGIA}

Os índices de Rasmussen-Hirschman (IRH) ${ }^{2}$ são a primeira definição na literatura que procura definir os setores-chave de uma economia, através da sua análise de ligação para frente e para trás, definindo setores-chave como sendo aqueles que apresentam ambas as ligações como sendo superiores a um. O índice de ligação para frente indica que a produção de determinado setor é amplamente utilizada pelos demais setores e o de ligação para trás, indica que o setor é altamente dependente dos demais.

Os mesmos podem ser obtidos a partir das seguintes expressões.

Índices de ligação para frente:

$$
U_{i}=\frac{\frac{1}{n} \sum_{j} b_{j}}{\frac{1}{n^{2}} \sum_{i} \sum_{j} b_{j}}, \text { onde }(i, j=1,2, \ldots, n)
$$

Índices de ligação para trás:

$$
U_{j}=\frac{\frac{1}{n} \sum_{i} b_{j}}{\frac{1}{n^{2}} \sum_{i} \sum_{j} b_{j}}, \text { onde }(i, j=1,2, \ldots, n)
$$

Os índices de ligações sugeridos por Hirschman-Rasmussen apresentam a desvantagem de não considerar os diferentes níveis de produção de cada setor da economia. Com o objetivo de suprir essa desvantagem, vêm surgindo diferentes abordagens para o cálculo de índices de ligações intersetoriais de uma economia, dentre eles o do índice puro de ligação (GHS) ${ }^{3}$.

O Índice GHS, criado por Guilhoto et al. (1996), que permite identificar o grau dos impactos na demanda final em determinados setores, bem como dimensionar as interações dos mesmos com o valor da produção. A ideia básica consiste em isolar determinado setor $j$ do restante da economia, visando definir

2 Para maior detalhamento desse índice, consultar Rasmussen (1956) e Hirschman (1958).

3 Em linhas gerais, os índices IRH avaliam, principalmente, os coeficientes técnicos de produção, preocupando-se com o quanto da tecnologia adotada por cada setor é dependente ou fornecedora de insumos. Os índices puros de ligação (GHS), por sua vez, avaliam a importância dos volumes fornecidos ou demandados. o efeito das ligações que esse setor $j$ da economia, ou seja, a diferença entre a produção total da economia e a produção na economia, caso o setor $j$ não comprasse insumos do resto da economia e não vendesse sua produção para o restante da economia. Essa situação equivale ao desaparecimento de todo o setor industrial.

Para isolar o setor $j$, considera-se um sistema de insumo-produto composto de dois setores representados pelo bloco da matriz $A$ de insumos diretos:

$$
A=\left[\begin{array}{cc}
A_{j j} & A_{\dot{r}} \\
A_{\dot{j}} & A_{r}
\end{array}\right]
$$

em que $A_{j j}$ e $A_{r r}$ representam matrizes quadradas de insumos diretos, no primeiro e no segundo setor, respectivamente, e $A_{j r}$ e $A_{r j}$ são matrizes retangulares dos insumos diretos adquiridos pelo segundo setor e vice-versa.

A partir de (7), pode-se chegar à seguinte expressão:

$$
B=(I-A)^{-1}=\left[\begin{array}{cc}
B_{j j} & B_{\dot{j}} \\
B_{\dot{j}} & B_{r}
\end{array}\right]=\left[\begin{array}{cc}
\Delta_{j} & 0 \\
0 & \Delta_{r}
\end{array}\right]\left[\begin{array}{cc}
\Delta_{j} & 0 \\
0 & \Delta_{r}
\end{array}\right]\left[\begin{array}{cc}
I & A_{\dot{j}} \Delta_{r} \\
A_{\dot{j}} \Delta_{j} & I
\end{array}\right]
$$

onde os componentes de (8) são definidos por:

$$
\begin{array}{ll}
\Delta_{j}=\left(I-A_{j}\right)^{-1}, & \Delta_{\mathrm{j}}=\left(I-\Delta_{j} A_{j} \Delta_{r} A_{\dot{j}}\right)^{-1} \\
\Delta_{r}=\left(I-A_{r}\right)^{-1}, & \Delta_{\mathrm{r}}=\left(I-\Delta_{r} A_{\dot{j}} \Delta_{j} A_{\dot{r}}\right)^{-1}
\end{array}
$$

ainda pela composição de (8), é possível verificar como ocorre o processo de produção na economia. Na matriz

$$
\left[\begin{array}{cc}
I & A_{\dot{j}} \Delta_{r} \\
A_{\dot{j}} \Delta_{j} & I
\end{array}\right]
$$

na primeira linha, temos a demanda final pela sua origem, ou seja, diferencia a demanda final interna, que vem de dentro do setor (I), da demanda final externa do setor $\left(A_{j r} D_{\eta}\right)$. o mesmo raciocínio pode ser aplicado a segunda linha.

Partindo-se da formulação de Leontief, $X=(I-A)^{-1} Y$, e utilizando-se as informações contidas em (8) e (10), derivam-se os índices puros:

$$
P B L=\Delta_{r} A_{\dot{j}} \Delta_{j} Y_{j} \quad \text { e } \quad P F L=\Delta_{j} A_{j} \Delta_{r} Y_{r} .
$$


O PBL indica o impacto puro do valor da produção total do setor $j$ no resto da economia $\left(D_{j} Y\right)$, isto é, o impacto que é livre da demanda de insumos que o setor $j$ produz para o próprio setor $j$ e dos retornos do resto da economia para o setor $j$, e vice-versa. O PFL indica o impacto puro do valor da produção total do resto da economia $\left(D_{j} Y\right)$ no setor $j$. Cabe salientar que tanto o PBL quanto o PFL são expressos em valores correntes e, portanto, podem ser somados para se obter o índice puro total das ligações (PTL).

Outro importante enfoque é o do Campo de Influência, este tipo de análise permite verificar como se distribuem as mudanças dos coeficientes diretos no sistema econômico como um todo, possibilitando determinar que relações entre os setores sejam mais importantes no processo produtivo. Uma descrição mais detalhada do desenvolvimento do conceito de campo de influência pode ser encontrada em Sonis et al. (1989) e Sonis et al. (1994).

Segundo Moretto (2000), o campo de influência é útil para verificar alterações nos coeficientes diretos de todo o sistema econômico, permitindo definir as relações intersetoriais que são mais importantes no processo de produção. A determinação do Campo de Influência faz uso da matriz de coeficiente técnicos de produção, $A=\left|a_{i j}\right|$, e da definição de uma matriz de variações incrementais nos coeficientes diretos de insumo, $E=\left|e_{i j}\right|$. Dessa forma, há uma mudança nas matrizes inversas de Leontief, $B=(I-A)^{-1}=\left|b_{i j}\right|$, passando, com as mudanças incrementais, a ser calculada da seguinte forma:

$$
B(\varepsilon)=[I-A-\varepsilon]^{-1}=\left|b_{i j}(\varepsilon)\right| .
$$

Caso a variação tecnológica seja pequena e só ocorra num coeficiente direto, tem-se que o campo de influência dessa variação pode ser aproximado em:

$$
F\left(\varepsilon_{i j}\right)=\frac{\left\lfloor B\left(\varepsilon_{j}\right)-B\right\rfloor}{\varepsilon_{j}},
$$

onde $F\left(\varepsilon_{i j}\right)$ é uma matriz $(n x n)$ do campo de influência do coeficiente $a_{i j}$

$\mathrm{Na}$ determinação dos coeficientes diretos que possuem maios campo de influência, associam-se cada matriz $F\left(\varepsilon_{i j}\right)$ a um valor, dado por:

$$
S_{i j}=\sum_{k=l}^{n} \sum_{l=1}^{n}\left[f_{k}\left(\varepsilon_{j}\right)\right]^{2} .
$$

Assim, os coeficientes diretos que possuem os maiores valores de $S_{i j}$ são os que possuem maior campo de influência na economia como um todo.

Uma análise complementar é a análise de impacto, onde a partir do modelo básico de Leontief $X=(I-A)^{-1} X$, pode ser mensurado o impacto que as mudanças ocorridas na demanda final $(Y)$, ou em cada um de seus componentes (consumo das famílias, gastos do governo, investimentos e exportações), teriam sobre a produção total, emprego, importações, impostos, salários etc. Assim, tem-se:

$$
\begin{aligned}
& \Delta X=(I-A)^{-1} \Delta Y \\
& \Delta V=\hat{v} \Delta X
\end{aligned}
$$

onde $\Delta Y$ e $\Delta X$ são vetores $(n x 1)$, representando, respectivamente, a estratégia setorial e os impactos sobre o volume da produção. Já $\Delta V$ é um vetor $(n \times 1)$ que representa o impacto sobre qualquer uma das variáveis tratadas acima, ou seja, emprego, importações etc. Tem-se também que $\hat{v}$ é uma matriz diagonal $(n \times n)$, em que os elementos da diagonal são, respectivamente, os coeficientes de emprego, salários, entre outros, que são obtidos a partir da divisão do valor utilizado das variáveis de cada setor na produção total, pela produção total do setor correspondente, isto é:

$$
v_{i}=\frac{V_{i}}{X_{i}}
$$

A partir dos coeficientes obtidos de (17) e da matriz inversa de Leontief, é possível estimar, para cada setor da economia, o quanto é gerado direta e indiretamente de emprego, importações, impostos etc. para cada unidade monetária produzida para a demanda final. Assim:

$$
\mathbb{G}_{j}=\sum_{i=1}^{n} b_{j} v_{i}
$$

onde $G V_{j}$ é o impacto total, direto e indireto, sobre a variável em questão; $b_{i j}$ é ij-ésimo elemento da matriz inversa de Leontief; e $v_{i}$ é o coeficiente direto da variável em questão.

A razão dos geradores pelo respectivo coeficiente direto gera os multiplicadores tipo I (MTI), que indicam quanto é gerado, direta e indiretamente, 
de emprego, impostos, salários etc. Por exemplo, o multiplicador de emprego indica a quantidade de empregos gerados, direta e indiretamente, para cada emprego direto criado. O multiplicador do i-ésimo setor seria dado então por:

$$
M_{i}=\frac{G_{i}}{v_{i}}
$$

Outro importante indicador é o multiplicador tipo II (MTII), possui a mesma forma analítica do MTI, porém, a diferença no MTII é que o mesmo torna a renda endógena na matriz inversa de Leontief ${ }^{4}$.

Os dados para este estudo referem-se e são provenientes das tabelas de insumo-produto fornecidas pelo Instituto Banco da Amazônia (Basa). Esses dados são projeções feitas principalmente em cima das variações do PIB, e foram atualizadas para o ano de 2003. A estrutura da MIP de 90 atividades foi agregada em 25 setores.

\section{RESULTADOS E DISCUSSÃO}

O resultado para os índices de encadeamento encontram-se na Tabela 1. Observou-se, nesses resultados, que pelo IRH os setores que mais se destacaram foram o Metalsiderúrgico (10) e Adubos e fertilizantes (20), pois estes setores apresentaram efeitos tanto para frente quanto para trás maiores que um. Ainda por esse índice, verifica-se que setores como Aves, bovinos e suínos; Serviços; e Outras culturas são considerados setores-chave na ligação para frente, ou seja, como fornecedores de insumos para outras atividades. Já Soja e milho (1); Eletroeletrônicos (13); Veículos (14); Indústria do mobiliário (16); Papel e gráfica (17); Indústria da borracha (18); Alimentícios (23); e Indústrias diversas (24) foram considerados setores-chave na ligação para trás.

Em termos de importância econômica, o estado do Pará tem como principais setores-chave os ligados à agricultura e aos serviços, pois o índice puro total normalizado mostra-se mais intenso para os setores ligados a essas atividades (Figura 1).

Um dos setores que mais de destaca é o de Adubo e fertilizantes (20), por ser considerado um setor-chave tanto no enfoque do IRH como no GHS, o que indica não apenas um forte inter-relacionamento com outros setores da economia, como também se trata de um setor de grande importância econômica, sendo o segundo e terceiro, respectivamente, na ligação para trás e para frente no índice puro.

4 O principal objetivo desse multiplicador é o de verificar se a renda e o consumo das famílias interferem no impacto setorial, ou seja, verificar o efeito renda entre os setores.

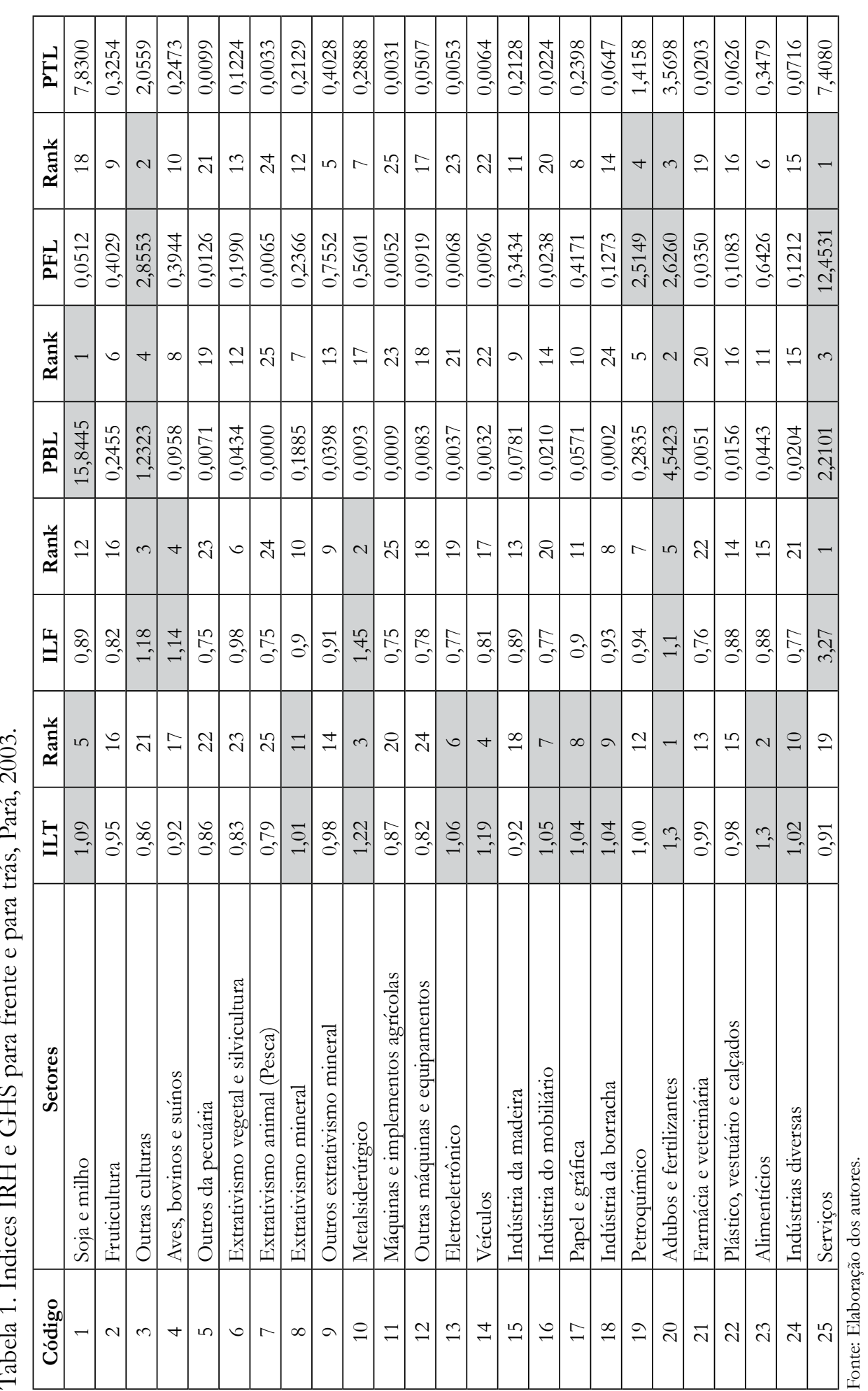




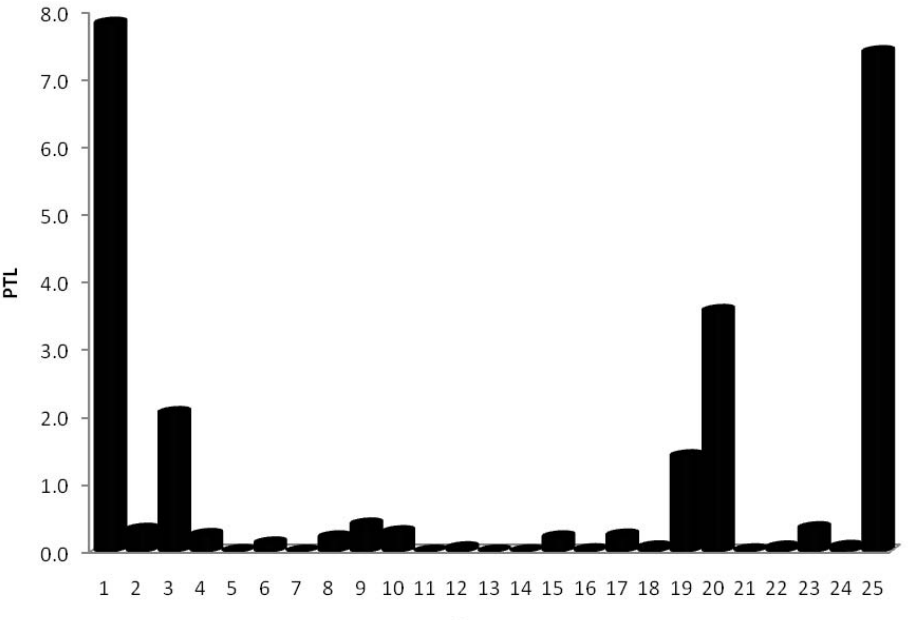

Setores

Figura 1. Índices puros de ligações totais normalizados, Pará, 2003.

Fonte: Elaboração dos autores.

Para o complemento da análise dos índices IRH, foi calculado o campo de influência. Para tanto, foram escolhidos 128 coeficientes setoriais que possuíam maior campo de influência ${ }^{5}$ na estrutura econômica do país, plotados na Figura 2 , cujos eixos discriminam os setores considerados nesse trabalho.

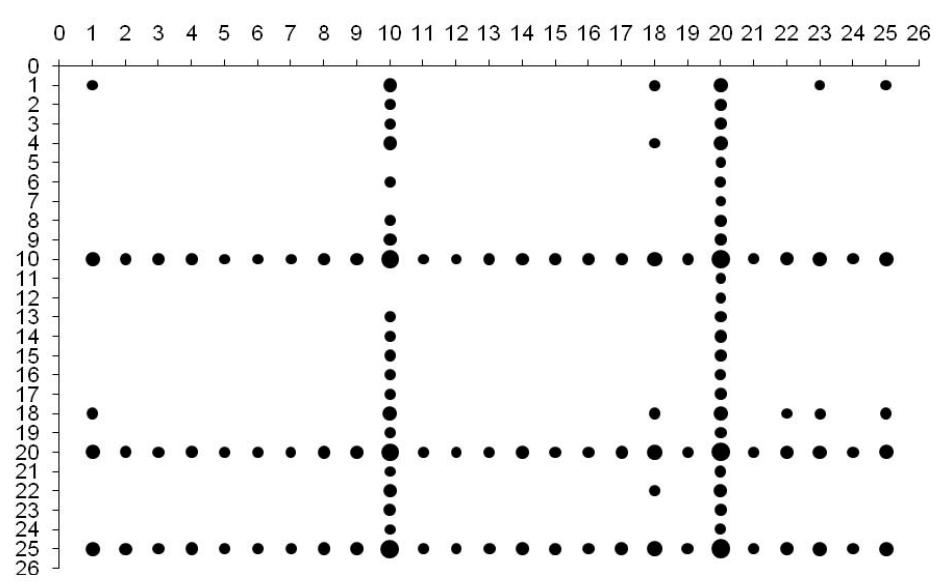

Figura 2. Coeficientes setoriais com maior campo de influência, Pará, 2003. Fonte: Elaboração dos autores.

Para o cálculo do campo de influência foi considerado um aumento de $1 \%$ na estrutura tecnológica da economia paraense, ou seja, mudanças diretas nos coeficientes de produção.
Pode-se perceber que, se ocorressem pequenas alterações nos coeficientes diretos de produção, o setor Adubos e fertilizantes (20) seria o grande propagador dessas alterações no sistema econômico paraense, visto que das maiores relações, foi o único que apresentou todos os coeficientes relativos à compra e venda entre os 25 setores analisados. O segundo maior propagado foi o setor Metalsiderúrgico, que apresentou todos os 25 coeficientes relativos à venda e 20 coeficientes envolvendo compras.

Considerando somente o lado das compras, ou seja, analisando a importância dos setores como compradores de insumos dos demais setores da economia, podem-se ressaltar: Serviços (25), Indústria da borracha (18) e Soja e milho (1). Nas vendas destacam-se também os setores: Indústria da borracha (18), Alimentícios (23) e Serviços (25).

Outra importante análise são os multiplicadores que permitem verificar como se modificaram a produção, a renda, o número de pessoas ocupadas na economia etc., quando a demanda final de cada um dos setores se altera. Isso pode acontecer, por exemplo, em decorrência de um aumento de investimento num determinado setor.

Os multiplicadores tipo I e tipo II (com o consumo da família exógeno e endógeno ao sistema produtivo, respectivamente) podem ser vistos na Tabela 2 . Observando a referida tabela, que apresenta uma ordenação dos multiplicadores em termos de magnitude, pode-se constatar que para alguns setores, existem uma grande diferença entre os multiplicadores, tanto do tipo I como do tipo II.

Para os multiplicadores de produção, os cinco maiores multiplicadores, considerando o consumo da família como exógeno, foram dos seguintes setores: Serviços (25); Metalsiderúrgico (10); Outras culturas (3); Aves, bovinos e suínos (4); e Adubos e fertilizantes (20). Já os cinco menores, de acordo com a estrutura produtiva para o ano de 2003, foram: Extrativismo animal (Pesca) (7); Máquinas e implementos agrícolas (11); Outros da pecuária (5); Farmácia e veterinária (21); e Indústria do mobiliário (16).

O setor de Serviços (25) apresenta-se como o setor mais impactante na produção, com um valor de $(4,39)$. Isso significa que um aumento de $\mathrm{R} \$ 1,00$ na demanda final sobre a produção, implicaria um aumento total na produção de $R \$ 4,39$, direta e indiretamente. Se esse valor for decomposto, pode-se notar que $\mathrm{R} \$ 1,00$ poderá ser direcionado para a demanda final do setor de Serviços, e $\mathrm{R} \$ 3,39$ poderão ser exigidos dos demais setores integrantes do processo produtivo da economia paraense. 
Considerando o consumo das famílias como endógeno ao sistema produtivo, algumas posições alteram-se, a exceção fica por parte do setor Alimentícios (23), que passa a se configurar como um dos cinco primeiros e Adubos e fertilizantes fica fora desse rank. Os cinco principais setores para os multiplicadores do tipo II foram: Serviços (25); Alimentícios (23); Aves, bovinos e suínos (4); Metalsiderúrgico (10); e Outras culturas (3). Os menores multiplicadores são aqueles que menos estão sujeitos ao consumo das famílias, são eles: Máquinas e implementos agrícolas (11); Extrativismo animal (7); Farmácia e veterinária (21); Eletroeletrônico (13); e Indústria do mobiliário (16).

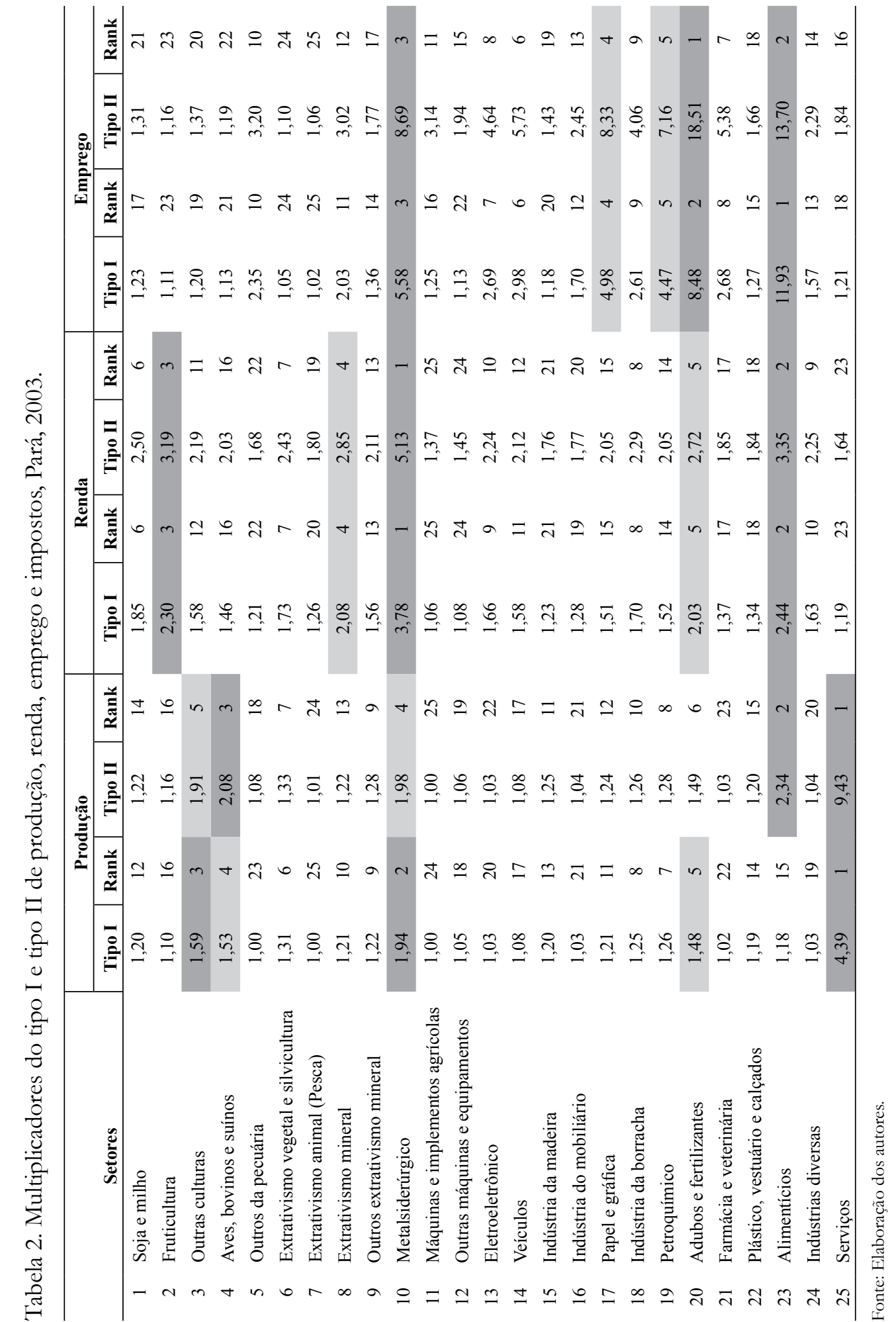


Os resultados do multiplicador tipo II deixam claro que o efeito renda é significativo na produção da economia paraense. O aumento percentual, por exemplo, no multiplicador de produção do setor Serviços foi de $115 \%$, porém, esse aumento percentual alto foi exceção; grande parte dos setores da economia paraense sofreram pouca influência do efeito renda na economia, tanto que a média do multiplicador de produto para todos os setores foi de 12,31\% (Tabela 3).

Tabela 3. Aumento percentual do multiplicador tipo I para o multiplicador tipo II (Efeito Renda).

\begin{tabular}{lccccc}
\hline \multicolumn{1}{c}{ Setores } & Produto & Renda & Emprego & Impostos & Importação \\
\hline Soja e milho & 1,40 & 35,63 & 6,42 & 25,90 & 10,66 \\
Fruticultura & 5,53 & 38,63 & 3,91 & 12,93 & 6,18 \\
Outras culturas & 20,29 & 39,03 & 13,86 & 15,58 & 7,41 \\
Aves, bovinos e suínos & 35,78 & 38,51 & 5,19 & 25,69 & 12,31 \\
Outros da pecuária & 7,75 & 38,90 & 36,17 & 23,60 & 9,25 \\
Extrativismo vegetal e silvicultura & 1,00 & 40,14 & 5,25 & 11,86 & 3,05 \\
Extrativismo animal (Pesca) & 0,87 & 43,00 & 4,02 & 27,58 & 30,10 \\
Extrativismo mineral & 0,58 & 36,90 & 48,61 & 16,46 & 10,87 \\
Outros extrativismo mineral & 4,88 & 34,65 & 30,16 & 11,67 & 21,59 \\
Metalsiderúrgico & 1,83 & 35,83 & 55,84 & 9,53 & 5,65 \\
Máquinas e implementos agrícolas & 0,06 & 29,50 & 150,15 & 73,89 & 110,98 \\
Outras máquinas e equipamentos & 0,86 & 34,27 & 71,64 & 66,28 & 112,65 \\
Eletroeletrônico & 0,15 & 34,80 & 72,39 & 11,68 & 19,54 \\
Veículos & 0,16 & 34,02 & 92,57 & 11,70 & 19,69 \\
Indústria da madeira & 4,18 & 43,87 & 21,24 & 39,48 & 92,16 \\
Indústria do mobilírio & 0,84 & 37,90 & 44,53 & 32,32 & 39,00 \\
Papel e gráfica & 2,68 & 35,32 & 67,26 & 21,52 & 11,26 \\
Indústria da borracha & 0,61 & 34,97 & 55,52 & 11,45 & 7,18 \\
Petroquímico & 1,17 & 34,83 & 60,30 & 20,97 & 22,12 \\
Adubos e fertilizantes & 0,53 & 34,37 & 118,22 & 21,15 & 10,81 \\
Farmácia e veterinária & 0,85 & 34,29 & 100,95 & 22,34 & 31,41 \\
Plástico, vestuário e calçados & 1,00 & 37,35 & 30,62 & 26,84 & 32,56 \\
Alimentícios & 99,17 & 37,09 & 14,84 & 16,07 & 17,53 \\
Indústrias diversas & 0,57 & 37,72 & 45,24 & 22,62 & 34,04 \\
Serviços & 115,01 & 38,01 & 51,80 & 46,19 & 48,48 \\
\hline Aumento Médio & 12,31 & 36,78 & 48,27 & 25,01 & 29,06 \\
\hline
\end{tabular}

Fonte: Elaboração dos autores.
O multiplicador de renda mostra os impactos na renda recebida pelas famílias, ocasionados por variações na demanda final. Optou-se por calcular os multiplicadores de renda que retratam a renda gerada em todos os setores da economia, resultante do aumento de $\mathrm{R} \$ 1,00$ de demanda final pelo produto de um determinado setor.

Analisando a Tabela 2, dada a estrutura produtiva do ano de 2003, podese verificar que os setores que apresentaram os maiores multiplicadores de renda foram: Metalsiderúrgico (10); Alimentícios (23); Fruticultura (2); Extrativismo mineral (8); e Adubo e fertilizantes (20). Os resultados coincidiram tanto para o multiplicador de renda tipo I quanto para o tipo II, para os cinco maiores, porém, a ordem dos mesmos difere. O destaque ficou para dois setores que no multiplicador de produto não se configuraram entre os principais, mas que se constituem como importantes atividades na economia paraense. Para Fruticultura, por exemplo, o aumento de $\mathrm{R} \$ 1,00$ na demanda final, gera direta e indiretamente um aumento na renda de $\mathrm{R} \$ 2,3$. Para o setor Extrativismo mineral o aumento direto e indireto na renda será de $\mathrm{R} \$ 2,08$.

Outro resultado relevante entre os multiplicadores de renda é o efeito renda, que gerou um aumento médio de 36,78\% no multiplicador, destacando-se o setor Indústria da madeira, com um aumento, devido ao efeito renda de 43,87\% no impacto de seu multiplicador.

O multiplicador de emprego é outro que permite verificar importantes resultados para a economia paraense. O multiplicador de emprego permite determinar o impacto de variações na demanda final sobre o produto que, por sua vez, leva a variações no emprego, as quais conduzem a uma variação na renda e, consequentemente, na demanda do consumidor.

Analisando a Tabela 2, verifica-se que os cinco setores com maiores multiplicadores de emprego (tanto para o multiplicador tipo I quanto para o tipo II), foram os seguintes: Alimentícios (23); Adubos e fertilizantes (20); Metalsiderúrgico (10); Papel e gráfica (17); e Petroquímico. Já os setores que menos empregam são: Extrativismo animal (pesca) (7); Extrativismo vegetal e silvicultura (6); Fruticultura (2); Outras máquinas e equipamentos (12), com exceção para o multiplicador tipo II; e Aves, bovinos e suínos (4).

A análise de geração direta, indireta e induzida de empregos foi feita levando-se em consideração o coeficiente de emprego. Dessa forma, foi analisado o número de empregos direto, indireto e induzido que poderiam ser gerados para 
cada R\$ 1 milhão em cada um dos 25 setores considerados no presente estudo. Os resultados encontram-se na Tabela 4.

Verifica-se que os setores Soja e milho (1); Fruticultura (2); Aves, bovinos e suínos (4); Extrativismo animal (Pesca) (7); e Extrativismo vegetal e silvicultura (6) são os cinco mais importantes geradores de emprego diretos, caso ocorra um aumento na demanda final, e esses cinco setores pertencem a uma das mais importantes atividades do estado que é a agropecuária.

Considerando a estrutura produtiva de 2003, os setores que menos gerariam empregos diretos seriam: Adubos e fertilizantes (20); Metalsiderúrgico (10); Petroquímico (19); Papel e gráfica (17); e Veículos (14), ou seja, são setores que na sua dinâmica são mais intensivos em capital. Apesar de empregarem poucas pessoas, dois desses setores são considerados chave na economia paraense, como Adubos e fertilizantes e Metalsiderúrgico.

Tabela 4. Empregos diretos, indiretos, induzidos e totais gerados devido a um aumento de R\$1 milhão na demanda final, 2003.

\begin{tabular}{|c|c|c|c|c|c|c|c|c|c|}
\hline & Setores & $\begin{array}{c}\text { Empregos } \\
\text { Diretos }\end{array}$ & Rank & $\begin{array}{l}\text { Empregos } \\
\text { Indiretos }\end{array}$ & Rank & $\begin{array}{l}\text { Empregos } \\
\text { Induzidos }\end{array}$ & Rank & \begin{tabular}{|c|} 
Empregos \\
Totais \\
\end{tabular} & Rank \\
\hline 1 & Soja e milho & 129 & 1 & 29 & 2 & 10 & 14 & 168 & 1 \\
\hline 2 & Fruticultura & 124 & 2 & 14 & 6 & 5 & 21 & 144 & 3 \\
\hline 3 & Outras culturas & 27 & 10 & 5 & 21 & 5 & 25 & 37 & 13 \\
\hline 4 & $\begin{array}{l}\text { Aves, bovinos e } \\
\text { suínos }\end{array}$ & 122 & 3 & 16 & 5 & 7 & 19 & 146 & 2 \\
\hline 5 & $\begin{array}{l}\text { Outros da } \\
\text { pecuária }\end{array}$ & 6 & 17 & 7 & 20 & 5 & 23 & 18 & 25 \\
\hline 6 & $\begin{array}{l}\text { Extrativismo } \\
\text { vegetal e } \\
\text { silvicultura }\end{array}$ & 82 & 5 & 4 & 22 & 5 & 24 & 91 & 6 \\
\hline 7 & $\begin{array}{l}\text { Extrativismo } \\
\text { animal (Pesca) }\end{array}$ & 118 & 4 & 2 & 24 & 5 & 22 & 125 & 4 \\
\hline 8 & $\begin{array}{l}\text { Extrativismo } \\
\text { mineral }\end{array}$ & 10 & 15 & 11 & 9 & 10 & 15 & 31 & 16 \\
\hline 9 & $\begin{array}{l}\text { Outros } \\
\text { extrativismo } \\
\text { mineral }\end{array}$ & 25 & 11 & 9 & 18 & 10 & 13 & 44 & 11 \\
\hline 10 & Metalsiderúrgico & 2 & 24 & 10 & 12 & 7 & 20 & 18 & 24 \\
\hline 11 & $\begin{array}{l}\text { Máquinas e } \\
\text { implementos } \\
\text { agrícolas }\end{array}$ & 11 & 14 & 3 & 23 & 21 & 3 & 34 & 14 \\
\hline 12 & $\begin{array}{l}\text { Outras máquinas } \\
\text { e equipamentos }\end{array}$ & 14 & 13 & 2 & 25 & 12 & 11 & 28 & 19 \\
\hline 13 & Eletroeletrônico & 5 & 18 & 9 & 15 & 11 & 12 & 25 & 20 \\
\hline 14 & Veículos & 5 & 21 & 10 & 11 & 14 & 8 & 28 & 18 \\
\hline 15 & $\begin{array}{l}\text { Indústria da } \\
\text { madeira }\end{array}$ & 76 & 6 & 14 & 7 & 19 & 4 & 109 & 5 \\
\hline
\end{tabular}

\begin{tabular}{|c|c|c|c|c|c|c|c|c|c|}
\hline & Setores & $\begin{array}{c}\text { Empregos } \\
\text { Diretos }\end{array}$ & Rank & $\begin{array}{c}\text { Empregos } \\
\text { Indiretos }\end{array}$ & Rank & \begin{tabular}{|l|} 
Empregos \\
Induzidos \\
\end{tabular} & Rank & \begin{tabular}{|c|}
$\begin{array}{c}\text { Empregos } \\
\text { Totais }\end{array}$ \\
\end{tabular} & Rank \\
\hline 16 & $\begin{array}{l}\text { Indústria do } \\
\text { mobiliário }\end{array}$ & 30 & 9 & 21 & 3 & 23 & 2 & 73 & 8 \\
\hline 17 & Papel e gráfica & 4 & 22 & 16 & 4 & 14 & 7 & 34 & 15 \\
\hline 18 & $\begin{array}{l}\text { Indústria da } \\
\text { borracha }\end{array}$ & 6 & 16 & 9 & 14 & 8 & 17 & 24 & 21 \\
\hline 19 & Petroquímico & 3 & 23 & 9 & 13 & 7 & 18 & 19 & 23 \\
\hline 20 & $\begin{array}{l}\text { Adubos e } \\
\text { fertilizantes }\end{array}$ & 1 & 25 & 9 & 16 & 12 & 10 & 22 & 22 \\
\hline 21 & $\begin{array}{l}\text { Farmácia e } \\
\text { veterinária }\end{array}$ & 5 & 20 & 9 & 17 & 14 & 6 & 29 & 17 \\
\hline 22 & $\begin{array}{l}\text { Plástico, } \\
\text { vestuário e } \\
\text { calçados }\end{array}$ & 42 & 7 & 11 & 8 & 16 & 5 & 69 & 9 \\
\hline 23 & Alimentícios & 5 & 19 & 59 & 1 & 10 & 16 & 74 & 7 \\
\hline 24 & $\begin{array}{l}\text { Indústrias } \\
\text { diversas }\end{array}$ & 18 & 12 & 11 & 10 & 13 & 9 & 42 & 12 \\
\hline 25 & Serviços & 36 & 8 & 8 & 19 & 23 & 1 & 67 & 10 \\
\hline
\end{tabular}

Fonte: Elaboração dos autores.

A análise da geração de empregos indiretos ${ }^{6}$ considerou, também, o efeito sobre o número de pessoas ocupadas em um setor, dado ao aumento de R\$1 milhão nos investimentos de outros setores. Na Tabela 4 esses resultados podem ser verificados.

Pelos resultados, verifica-se que dois setores da atividade agropecuária mantêm-se como principais geradores de empregos indiretos \{Soja e milho (1); e Aves, bovinos e suínos (4)\}, e parte do investimento direciona-se para setores interligados a agropecuária como os setores Alimentícios (23); Papel e gráfica (17); e Indústria do mobiliário (16).

Pela análise dos empregos induzidos ${ }^{7}$, encontram-se na Tabela 4. De acordo com os resultados, os setores que mais geraram empregos induzidos foram: Serviços (25); Indústria do mobiliário (16); Máquinas e implementos agrícolas (11); Indústria da madeira (15); e Plástico, vestuário e calçados. Já os setores que menos geraram empregos induzidos foram aqueles ligados à agropecuária.

Na obtenção de uma estimativa de novos empregos indiretos gerados, levou-se em consideração o somatório do coeficiente de emprego multiplicado pela matriz inversa de Leontief. Dessa forma, têm-se os novos empregos gerados direta e indiretamente e, subtraindo os empregos diretos calculados, obtêm-se somente os novos empregos gerados de forma indireta.

A análise do potencial de geração de empregos induzidos considera a endogeneização do consumo das famílias. Assim, na obtenção do número de empregos induzidos gerados na economia, leva-se em consideração o somatório do coeficiente de emprego multiplicado pela matriz inversa de Leontief, com o consumo das famílias considerado endógeno; em seguida subtrai-se destes valores o somatório dos coeficientes de emprego multiplicado pela matriz inversa de Leontief. Dessa forma, elimina-se a dupla contagem dos empregos diretos e indiretos. 
Nos empregos totais (que é a soma do direto, indireto e induzido), a configuração é semelhante a dos empregos diretos, estando entre os maiores empregadores setores ligados à agropecuária.

$\mathrm{Na}$ composição do emprego total, os setores que empregam maior impacto no emprego direto na economia paraense (Figura 3), a maior parte pertence aos setores ligados à agropecuária, com exceção de Plásticos, vestuários e calçados (22). No emprego indireto, os setores com maior composição são: Extrativismo mineral (8); Metalsiderúrgico (10); Papel e gráfica (17); Indústria da borracha (18); Petroquímico (19); Alimentícios (23); e Outros da pecuária (5). E, finalmente, os setores que mais emprego criam de forma induzida são: Outros extrativismo mineral (9); Máquinas e implementos agrícolas (11); Outras máquinas e implementos (12); Eletroeletrônico (13); Veículos (14); Indústria da madeira (15); Indústria do mobiliário (16); Adubos e fertilizantes (20); Farmácia e veterinária (21); Indústrias diversas (24); e Serviços (25).

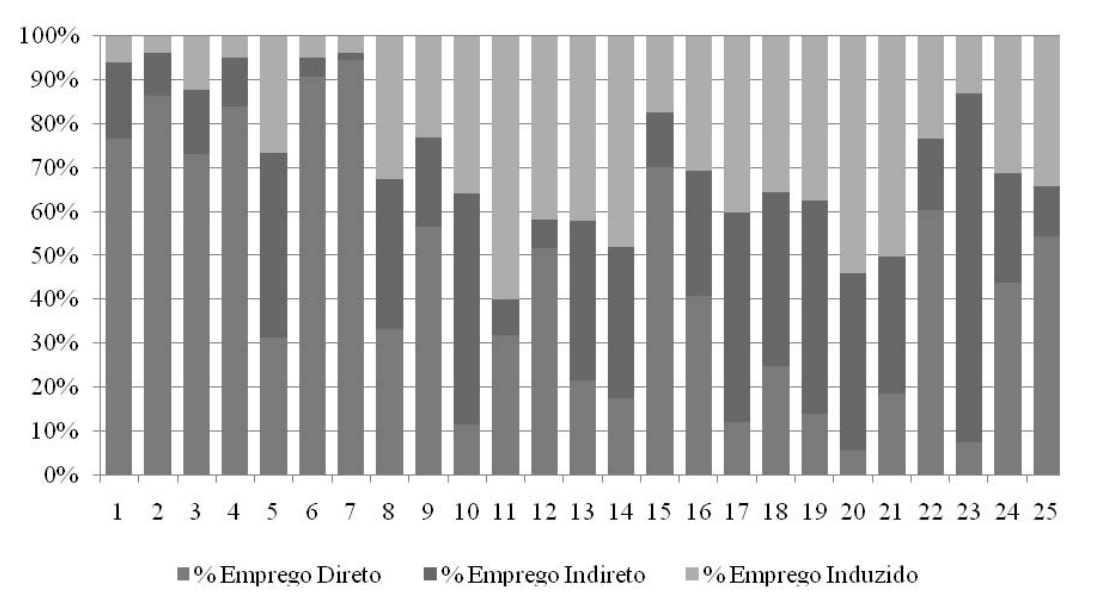

Figura 3. Composição do emprego total gerado devido a um aumento de $\mathrm{R} \$ 1$ milhão na demanda final, Pará, 2003.

Fonte: elaboração dos autores.

\section{CONCLUSÃO}

Este trabalho teve como objetivo identificar os principais setores da economia paraense por meio de um modelo insumo-produto, no ano de 2003 e, a partir desse modelo, mensurar e analisar as relações intersetoriais, bem como a capacidade de indução dos investimentos sobre o crescimento da economia.
As informações são oriundas das matrizes de insumo-produto da Amazônia e dos estados da Região (1999) do Banco da Amazônia, e foram atualizadas para o ano de 2003.

A mensuração e análise dos índices de ligações intersetoriais permitiram a identificação dos setores-chave, considerando o modelo de insumo-produto construído e o nível de agregação utilizado. Dentre os setores, foram cinco os considerados como chave, pelos critérios do IRH, GHS e Campo de Influência: Soja e milho (1); Outras culturas (3); Metalsiderúrgico (10); Adubos e fertilizantes (20); e Serviços (25). Dessa forma, aumentos de investimentos nestes setores tendem a ampliar a capacidade de crescimento da economia do estado do Pará.

A análise dos impactos que poderiam ocorrer na produção, renda e emprego, caso ocorressem variações na demanda final, mostrou que dos setores que apresentaram os maiores multiplicadores, três pertencem à agropecuária (Fruticultura; Outras culturas; e Aves, bovinos e suínos), dois estão ligados à siderurgia e mineração (Extrativismo mineral e Metalsiderúrgico), dois ligados ao setor químico (Petroquímico e Adubos e fertilizantes), o setor Alimentício, o setor de Serviços e o setor de Papel e gráfica. Na composição do emprego total, o emprego direto é o que mais aumenta com o impacto na demanda final, pois o mesmo representa em média 44,45\% na composição do emprego total. O emprego induzido contribui em $28,55 \%$ em média e o emprego indireto representa $27 \%$.

Em suma, é importante ressaltar que é fundamental conhecer a interdependênica produtiva dos estados, o que respalda a contribuição deste trabalho para discussões de planejamento e desenvolvimento do estado do Pará. Entretanto, as questões aqui abordadas não esgotam o campo de investigação sobre as relações intersetoriais do estado. A possibilidade de estudar as relações inter-regionais e internacionais dos setores, definidos nessa pesquisa como setores dinâmicos do estado, seriam contundentes, além de complementares a este estudo.

\section{REFERÊNCIAS}

GUILHOTO, J. J. M.; SONIS, M.; HEWEINGS, G. J. D. Linkages and multipliers in a multiregional framework: integration of alternative approaches. Illinois: University of Illinois/Regional Economics Applications Laboratory, 1996. (Discussion Paper 96-T-8). 
HIRSCHMAN, A. O. The strategy of economic development. New Haven: Yale University Press, 1958.

LEONTIEF, W. A economia de insumo-produto. São Paulo: Fundo de Cultura, 1983.

MORETTO, A. C. Relações intersetoriais e inter-regionais na economia paranaense em 1995. 2000. 161f. (Doutorado) - Escola Superior de Agronomia Luiz de Queiroz, Universidade de São Paulo, Piracicaba, 2000.

RASMUSSEN, P. Studies in intersectorial relations. Amsterdam: North Holland, 1956.

SANTANA, A. C. A dinâmica do complexo agroindustrial e o crescimento econômico no Brasil. 1994. 302f. (Doutorado) - Departamento de Economia Rural, Universidade Federal de Viçosa, Viçosa, 1994.

SILVA, L. M. S. Relações intersetoriais da economia acreana e sua inserção na economia brasileira: uma análise insumo-produto. 2004. 184f. (Mestrado) Departamento de Economia Aplicada, Universidade de São Paulo, Piracicaba, 2004. SONIS, M.; HEWINGS, G. J. D. Error and sensitivy input-output analisys: a new aproach. In: MILLER, R. E. et al. (Ed.). Frontiers of input-output analysis. New York: Oxford University Press, 1989.

Fields of influence in input-output systems. Urbana: University of Illinois/Regional Economics Applications Laboratory, 1994.

VALVERDE, S. R.; REZENDE, J. L. P.; SILVA, M. L.; JACOVINE, L. A.; CARVALHO, R. M. M. Efeitos multiplicadores da economia florestal brasileira. Revista Árvore, v. 27, n. 3, p. 285-299, 2003. 